Hua-Rui Wang*

\title{
The crystal structure of poly[diaqua- $\left(\mu_{2}-1,2,4,5-\right.$ tetrakis(1,2,4-triazol-1-ylmethyl)-benzene- K2N: $\left.N^{\prime}\right)$-bis $\left(\mu_{3}\right.$-terephthalato- $\left.\mathrm{K}^{3} 0: 0^{\prime}: 0^{\prime \prime}\right)$ dicadmium(II)], $\mathrm{C}_{17} \mathrm{H}_{15} \mathrm{~N}_{6} \mathrm{O}_{5} \mathrm{Cd}$
}

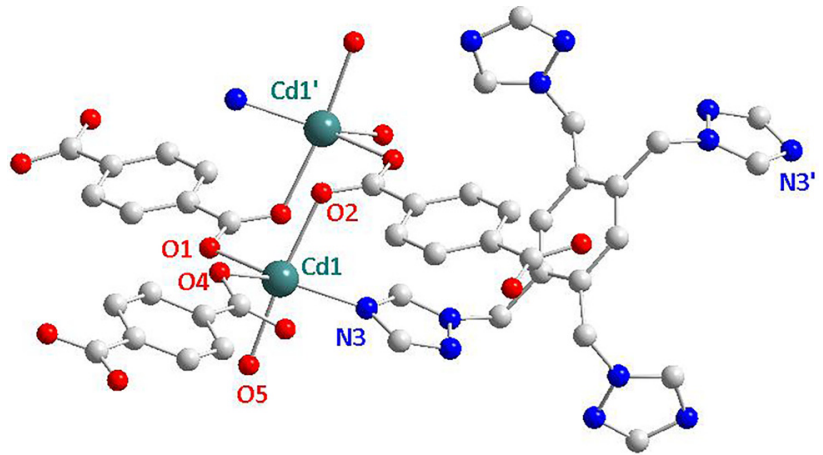

https://doi.org/10.1515/ncrs-2021-0427

Received November 2, 2021; accepted January 4, 2022;

published online January 14, 2022

\section{Abstract}

$\mathrm{C}_{17} \mathrm{H}_{15} \mathrm{~N}_{6} \mathrm{O}_{5} \mathrm{Cd}$, monoclinic, $P 2_{1} / c$ (no. 14), $a=10.095(2) \AA$, $b=13.380(3) \AA, \quad c=14.968(5) \AA, \quad \beta=115.16(2)^{\circ}$, $V=1829.9(9) \AA^{3}, Z=4, R_{g t}(F)=0.0267, w R_{r e f}\left(F^{2}\right)=0.0602$, $\mathrm{T}=293(2) \mathrm{K}$

CCDC no.: 2132326

A part of the title crystal structure is shown in the figure. Table 1 contains crystallographic data and Table 2 contains the list of the atoms including atomic coordinates and displacement parameters.

\section{Source of material}

Terephthalic acid (0.017 g, $0.1 \mathrm{mmol})$, 1,2,4,5-tetrakis(1,2,4-triazol-1-ylmethyl)-benzene(0.04 g, $0.1 \mathrm{mmol})$ and Cadmium(II) acetate $(0.023 \mathrm{~g}, 0.1 \mathrm{mmol})$ were added to the mixture of water $(7 \mathrm{~mL})$ and 1,4-dioxane $(1 \mathrm{~mL})$ in a Teflonlined stainless steel reactor. The mixture was heated at $403 \mathrm{~K}$

*Corresponding author: Hua-Rui Wang, Henan Key Laboratory of Function-Oriented Porous Materials, College of Chemistry and Chemical Engineering, LuoYang Normal University, Luoyang, Henan 471934, P. R. China, E-mail: wanghrly@126.com. https://orcid.org/ 0000-0003-4069-3350
Table 1: Data collection and handling.

\begin{tabular}{|c|c|}
\hline Crystal: & Colorless block \\
\hline Size: & $0.23 \times 0.18 \times 0.11 \mathrm{~mm}$ \\
\hline Wavelength: & Mo $\mathrm{K} \alpha$ radiation $(0.71073 \AA$ ) \\
\hline$\mu:$ & $1.24 \mathrm{~mm}^{-1}$ \\
\hline Diffractometer, scan mode: & Rigaku Saturn 724, $\omega$ \\
\hline$\theta_{\text {max }}$, completeness: & $27.9^{\circ}, 99 \%$ \\
\hline$N(h k l)_{\text {measured }}, N(h k l)_{\text {unique }}, R_{\text {int }}:$ & $14,601,4324,0.021$ \\
\hline Criterion for $I_{\mathrm{obs}}, N(h k l)_{\mathrm{gt}}$ : & $I_{\text {obs }}>2 \sigma\left(I_{\text {obs }}\right), 3964$ \\
\hline$N(\text { param })_{\text {refined }}:$ & 262 \\
\hline Programs: & CrysAlis $^{\mathrm{PRO}}[1]$, Olex2 [2], SHELX [3, 4] \\
\hline
\end{tabular}

for three days, and then slowly cooled down to room temperature. Colorless crystals of the title compound were obtained.

\section{Experimental details}

The crystallographic data of title complex was collected on a Rigaku Saturn 724 CCD diffractometer at room temperature. Absorption corrections were applied by using multi-scan program [1]. Using Olex2 [2], the structure was solved with the ShelXT [3] structure solution program using Intrinsic Phasing and refined with the ShelXL [4] refinement package. The $\mathrm{H}$ atoms bonded to $\mathrm{C}$ atoms were fixed, with $\mathrm{C}-\mathrm{H}$ distance of $0.93 \AA$ A; and/or positioned geometrically in the riding-model approximation; $U_{\text {iso }}(\mathrm{H})=1.2 U_{\text {eq }}(\mathrm{C}), U_{\text {iso }}(\mathrm{H})=1.5 U_{\text {eq }}(\mathrm{O})$.

\section{Comment}

In order to obtain unique Metal Organic Frameworks (MOFs) with interesting properties, many flexible ligands have been widely employed as linkers of metal ions, specifically flexible $\mathrm{N}$-donor bridging ligands [5-8]. For example, 1,2,4-triazole and its derivatives as high versatile organic linkers can combine the advantages of coordination geometries of both pyrazole and imidazole. To date, there are a great number of MOFs based on flexible bis(triazole) or 
Table 2: Fractional atomic coordinates and isotropic or equivalent isotropic displacement parameters $\left(\AA^{2}\right)$.

\begin{tabular}{|c|c|c|c|c|}
\hline Atom & $x$ & $y$ & $z$ & $U_{\text {iso }} * / U_{\text {eq }}$ \\
\hline d1 & $0.69731(2)$ & $0.52986(2)$ & $0.49723(2)$ & $0.02830(6)$ \\
\hline 01 & $0.54310(18)$ & $0.65333(14)$ & $0.42584(16)$ & $0.0529(5)$ \\
\hline 02 & $0.3907(2)$ & $0.52589(12)$ & $0.38765(13)$ & $0.0391(4)$ \\
\hline 03 & $-0.0156(2)$ & $0.97370(13)$ & $0.12116(16)$ & $0.0512(5)$ \\
\hline 04 & $-0.17047(18)$ & 0.85225 (13) & $0.10329(13)$ & 0.0419 (4) \\
\hline 05 & $0.7696(2)$ & $0.56700(13)$ & $0.37052(14)$ & $0.0490(5)$ \\
\hline $5 \mathrm{~A}$ & 0.768858 & 0.631108 & 0.361873 & $0.074^{*}$ \\
\hline H5B & 0.849308 & 0.535328 & 0.374643 & $0.074^{*}$ \\
\hline N1 & $0.8028(2)$ & $-0.09000(15)$ & $0.44466(17)$ & $0.0418(5)$ \\
\hline N2 & $0.6548(2)$ & $0.21482(13)$ & $0.41310(14)$ & 0.0324 (4) \\
\hline 3 & $0.7071(2)$ & $0.36886(14)$ & $0.46086(15)$ & $0.0335(4)$ \\
\hline 14 & $0.8016(2)$ & $0.21604(15)$ & $0.46764(18)$ & $0.0427(5)$ \\
\hline 15 & $.8129(4)$ & $31(2)$ & $0.3624(2)$ & $0.0741(9)$ \\
\hline 6 & 7871 (3) & $-0.22416(18)$ & $0.3591(2)$ & $0.0584(7)$ \\
\hline $\mathrm{C} 1$ & $0.4178(2)$ & $0.61672(18)$ & $0.38198(17)$ & $0.0338(5)$ \\
\hline $\mathrm{C} 2$ & $0.2976(2)$ & $0.68747(16)$ & $0.32109(15)$ & $0.0284(4)$ \\
\hline $\mathrm{C} 3$ & $0.3295(2)$ & 0.78700 (18) & $0.31315(18)$ & 0.0377 (5) \\
\hline H3 & & & & $0.045^{\star}$ \\
\hline $\mathrm{C} 4$ & $0.2206(3)$ & $0.85246(17)$ & $0.25595(18)$ & $0.0371(5)$ \\
\hline $\mathrm{H} 4$ & 0.243427 & 0.918796 & 0.250246 & $0.044^{*}$ \\
\hline $\mathrm{C} 5$ & $.0774(2)$ & 0.8195 & 0.2070 & $05(4)$ \\
\hline C6 & $0.0451(2)$ & 0.7204 & 0.21753 (18) & $0.0371(5)$ \\
\hline H6 & & & & $0.045^{\star}$ \\
\hline $\mathrm{C} 7$ & $0.1541(2)$ & $0.65458(17)$ & $0.27293(18)$ & $0.0362(5)$ \\
\hline $\mathrm{H} 7$ & 0.131470 & 0.588067 & 0.278027 & $0.043^{*}$ \\
\hline $\mathrm{C} 8$ & $-0.0427(3)$ & $0.88747(18)$ & 0.1401 & $0.0349(5)$ \\
\hline C9 & $6002(3)$ & $0.30581(17)$ & $0.40955(18)$ & $0.0350(5)$ \\
\hline H9 & 501906 & 0.322801 & 0.376122 & $0.042^{*}$ \\
\hline C10 & $0.8277(3)$ & 0.30977 (18) & $0.4944(2)$ & $0.0400(6)$ \\
\hline $\mathrm{H} 10$ & & & & $0.048^{\star}$ \\
\hline C11 & $0.5789(3)$ & $0.12136(17)$ & $0.36742(18)$ & $0.0375(5)$ \\
\hline $\mathrm{H} 11 \mathrm{~A}$ & 0.640560 & 0.082966 & 0.345028 & $0.045^{\star}$ \\
\hline H11B & 489345 & 0.137513 & 0.310085 & $0.045^{*}$ \\
\hline C12 & $0.4015(3)$ & $0.06306(17)$ & $0.43193(18)$ & $0.0360(5)$ \\
\hline H12 & 0.334388 & 0.105893 & 0.385918 & $0.043^{*}$ \\
\hline C13 & $0.5419(3)$ & $0.05784(16)$ & $0.43776(17)$ & $0.0332(5)$ \\
\hline C14 & $0.6431(3)$ & $-0.00632(17)$ & $0.50736(18)$ & $0.0340(5)$ \\
\hline C15 & $0.7984(3)$ & $-0.01981(18)$ & $0.5178(2)$ & $0.0417(6)$ \\
\hline $\mathrm{H} 15 \mathrm{~A}$ & 0.836779 & 0.044253 & 0.509508 & $0.050^{*}$ \\
\hline H15B & 0.859955 & -0.044319 & 0.583460 & $0.050^{*}$ \\
\hline C16 & $0.7869(4)$ & $-0.1878(2)$ & $0.4405(2)$ & 0.0559 (8) \\
\hline H16 & 0.776816 & -0.226183 & 0.489033 & $0.067^{\star}$ \\
\hline C17 & $0.8006(4)$ & $-0.1418(2)$ & $0.3129(3)$ & $0.0680(10)$ \\
\hline H17 & 0.801270 & -0.143403 & 0.251009 & $0.082^{\star}$ \\
\hline
\end{tabular}

tri(triazole) ligands, such as 1,4-bis(1,2,4-triazol-1-ylmethyl) benzene or 1,3,5-tris(1,2,4-triazol-1-ylmethyl)-2,4,6-trimethylbenzene, but the MOFs built by flexible tetra(triazole) ligands are relatively limited [9-12]. The combination of N/O-donor ligands should better satisfy the coordination needs of metal ions and change the dimensionality
[13-17]. On the basis of the above considerations, we choose the flexible tetrapodal 1,2,4,5-tetrakis(1,2,4-triazol-1-ylmethyl)-benzene (ttyb) as a functional ligand and employ "mix-ligand" synthetic strategy to explore the assembly with "mixed" ttyb and aromatic polycarboxylate ligands. In this context, we reacted ttyb with $\mathrm{Cd}^{2+}$ ions, then employed terephthalic acid/ terephthalate (PTA) ligand as an auxiliary ligand, which features one two-dimensional structure, namely $\left[\mathrm{Cd}(\mathrm{PTA})(\mathrm{ttyb})_{0.5}\left(\mathrm{H}_{2} \mathrm{O}\right)\right]$.

$\mathrm{X}$-ray analysis reveals that title complex I crystallizes in monoclinic space group $P 21 / c$. The asymmetric unit of title complex contains one independent $\mathrm{Cd}(\mathrm{II})$ cation, one $\mathrm{PTA}^{2-}$ anion, one coordinated $\mathrm{H}_{2} \mathrm{O}$ and one half of a ttyb ligand. Each $\mathrm{Cd}$ center is five coordinated by three carboxylic $\mathrm{O}$ atoms from three $\mathrm{PTA}^{2-}$ anions, one $\mathrm{N}$ atoms from ttyb ligand and one water molecules to form a slight distorted trigonal bipyramidal geometry. The completely deprotonated PTA $^{2-}$ ligand, in which one carboxylate group adopts the bidentate chelate mode and the other adopts monodentate mode, acts as a $\mu_{2}$ bridging ligand two $\mathrm{Cd}(\mathrm{II})$ ions. The $\mathrm{PTA}^{2-}$ ligands link the $\mathrm{Cd}(\mathrm{II})$ via $\mathrm{Cd}-\mathrm{O}$ coordination interactions to give a 2D network with $\mathrm{Cd}_{2}(\mathrm{COO})_{4}$ subunits. ttyb acts as $\mu_{2}$-bridge linking two $\mathrm{Cd}(\mathrm{II})$ ions, and cannot connect the 2D layer to extend to a 3D network. The $\mathrm{Cd}-\mathrm{O}$ lengths are in the range of 2.2089(18) $-2.369(2) \AA$. The $\mathrm{Cd}-\mathrm{N}$ lengths are 2.235(2) $\AA$. Comparing I with $\left\{\left[\mathrm{Cd}_{2}(\mathrm{~L})_{2}\left(\mathrm{SO}_{4}\right)_{2}\left(\mathrm{H}_{2} \mathrm{O}\right)\right] 2 \mathrm{H}_{2} \mathrm{O}\right\}_{\mathrm{n}}$ (II, $\mathrm{L}=1,2,4,5-$ -tetrakis(imidazol-1-ylmethyl)benzene) [9], both of which prepared from the similar starting reactants, some important similarities and differences can be found as follows: (i) The coordination mode of tetradentate ligands. In I, ttyb acts function as a bidentate ligand to coordinate two $\mathrm{Cd}$ atoms using two flexible arms containing $\mathrm{N}$ atoms, another two 1,2,4-triazol groups do not take part in the coordination. In II, there are two ligands L (LA and LB) with different conformations in the asymmetric unit of II. Ligand LA serves as a tetradentate ligand to coordinate with four $\mathrm{Cd}$ atoms and ligand LB acts as a bidentate ligand to coordinate two $\mathrm{Cd}$ atoms. (ii) Different conformations of the tetradentate ligands. In I, ttyb adopts an up, up, down, down-conformation. In II, LA has an up, down, down, up-conformation and ligand LB adopts a peculiar $\mathrm{H}$-type conformation. Subsequent studies about this flexible tetrapodal ligand are underway. Many further attempts on developing new complexes with ttyb as the first ligand, such as by the use of other solvents, introducing other N/O-donor bridging or polycarboxylate ligands have been implemented in our laboratory. 
Author contributions: The author has accepted responsibility for the entire content of this submitted manuscript and approved submission.

Research funding: This work was supported by Key Scientific Research Projects of Higher Education of Henan Province (16A150016, DOI: 10.13039/501100013066) and Henan Province Natural Science Foundation (182300410237, DOI: 10.13039/501100006407).

Conflict of interest statement: The author declares no conflicts of interest regarding this article.

\section{References}

1. Oxford Diffraction Ltd. CrysAlis ${ }_{\mathrm{PRO}}$. Rigaku: Abingdon, Oxfordshire, England, 2006.

2. Dolomanov 0. V., Bourhis L. J., Gildea R. J., Howard J. A. K., Puschmann H. OLEX2: a complete structure solution, refinement and analysis program. J. Appl. Crystallogr. 2009, 42, 339-341.

3. Sheldrick G. M. SHELXTL - integrated space-group and crystalstructure determination. Acta Crystallogr. 2015, A71, 3-8.

4. Sheldrick G. M. Crystal structure refinement with SHELXL. Acta Crystallogr. 2015, C71, 3-8.

5. Chang X.-H., Yang X.-G., Zhai Z.-M., Chen J.-Y., Li F.-F. Synthesis, structure and highly enhanced phosphorescence of a cadmium(II) coordination polymer assembled with

1,4-naphthalenedicarboxylic acid and 2-propylimidazole. Chin. J. Struct. Chem. 2021, 40, 187-192.

6. Yang X. G., Ma L. F., Yan D. P. Facile synthesis of 1D organicinorganic perovskite micro-belts with high water stability for sensing and photonic applications. Chem. Sci. 2019, 10, 4567-4572.

7. Yang X. G., Zhai Z. M., Lu X. M., Zhao Y., Chang X. H., Ma L. F. Room temperature phosphorescence of $\mathrm{Mn}$ (II) and $\mathrm{Zn}$ (II) coordination polymers for photoelectron response applications. Dalton Trans. 2019, 48, 10785-10789.

8. Sharma R.-P., Saini A., Kumar J., Kumar S., Venugopalan P., Ferretti V. Coordination complexes of copper(II) with herbicidetrichlorophenoxyacetate: syntheses, characterization, single crystal X-ray structure and packing analyses of monomeric $\left[\mathrm{Cu}(-\mathrm{pic})_{3}(2,4,5\right.$-trichlorophenoxyacetate) $] \cdot \mathrm{H}_{2} \mathrm{O}$, [trans-
$\mathrm{Cu}(\mathrm{en})_{2}$ (2,4,5-trichlorophenoxyacetate $\left.)_{2}\right] \cdot 2 \mathrm{H}_{2} \mathrm{O}$ and dimeric $\left[\mathrm{Cu}_{2}(\mathrm{H} 2 \text { tea })_{2}(2,4,5 \text {-trichlorophenoxyacetate })_{2}\right] \cdot 2\left(\mathrm{H}_{2} \mathrm{O}\right)$. Inorg. Chim. Acta 2017, 457, 59-68.

9. Xu G.-C., Hua Q., Okamura T., Bai Z.-S., Ding Y.-J., Huang Y.-Q., Liu G.-X., Sun W.-Y., Ueyama N. Cadmium(ii) coordination polymers with flexible tetradentate ligand 1,2,4,5-tetrakis(imidazol1-ylmethyl)benzene: anion effect and reversible anion exchange property. CrystEngComm 2009, 11, 261-270.

10. Hua Q., Zhao Y., Xu G.-C., Chen M.-S., Su Z., Cai K., Sun W.-Y. Synthesis, structures, and properties of zinc(II) and cadmium(II) complexes with 1,2,4,5-tetrakis(imidazol-1-ylmethyl)benzene and multicarboxylate ligands. Cryst. Growth Des. 2010, 10, 2553-2562.

11. Fenton H., Tidmarsh I. S., Ward M. D. Homonuclear and heteronuclear complexes of a four-armed octadentate ligand: synthetic control based on matching ligand denticity with metal ion coordination preferences. Dalton Trans. 2009, 21, 4199-4207.

12. Hua Q., Su Z., Zhao Y., Okamura T., Xu G. C., Sun W.-Y., Ueyama N. Synthesis, structure and property of manganese(II) complexes with mixed tetradentate imidazole-containing ligand and benzenedicarboxylate. Inorg. Chim. Acta 2010, 363, 3550-3557.

13. Dang L.-L., Li T.-T., Cui Z., Sui D., Ma L.-F., Jin G.-X. Selective construction and stability studies of molecular trefoil knot and Solomon link. Dalton Trans. 2021, 50, 16984-16989.

14. Qin J.-H., Xu P., Huang Y.-D., Xiao L.-Y., Lu W., Yang X.-G., Ma L., Zang S.-Q. High loading of Mn(II)-metalated porphyrin in MOF for photocatalytic $\mathrm{CO}_{2}$ reduction in gas-solid condition. Chem. Commun. 2021, 57, 8468-8471.

15. Xue X.-F., Liu Y.-Q., Liu Q., Wang X.-Y., Li W. Four novel coordination polymers based on flexible 1,4-bis(1,2, 4-triazol-1-ylmethyl)benzene ligand: synthesis, structure, luminescence and magnetic properties. J. Cluster Sci. 2019, 30, 777-787.

16. Qin J. H., Zhang H., Sun P., Huang Y. D., Shen Q., Yang X. G., Ma L. F. Ionic liquid induced highly dense assembly of porphyrin in MOF nanosheets for photodynamic therapy. Dalton Trans. 2020, 49, 17772-17778.

17. Chang X.-H., Qin J.-H., Han M.-L., Ma L.-F., Wang L.-Y. Exploring the structural diversities and magnetic properties of copper(II) and manganese(II) complexes based on 5-methoxyisophthalate and flexible bis(imidazole) ligands. CrystEngComm 2014, 16, 870-882. 